\title{
Metodología para la determinación del crecimiento de la mancha urbana en las capitales de la región centroamericana (1975-1995-2014)
}

\section{Methodology for determining the growth of urban sprawl in the capital cities of the Central American region (1975-1995-2014)}

\author{
Christian Vargas-Bolaños ${ }^{1}$ \\ Centro Nacional de Alta Tecnología, Costa Rica \\ Ricardo Orozco-Montoya ${ }^{2}$ \\ Universidad Nacional, Costa Rica \\ Annie Vargas-Hernández ${ }^{3}$ \\ Secretaría Técnica Nacional Ambiental, Costa Rica \\ Jairo Aguilar-Arias ${ }^{4}$ \\ Fundación Promotora de Vivienda, Costa Rica
}

\begin{abstract}
Resumen
Este trabajo presenta la implementación de una metodología para la determinación del crecimiento de la mancha urbana de las ciudades capitales de la Región Centroamericana (RC), en el periodo 1975-1995-2014. El objetivo de la investigación es generar la mancha urbana de las ciudades capitales centroamericanas de los años de estudio mediante una metodología con sensores remotos y la implementación de diversas técnicas para el procesamiento y post-procesamiento de las imágenes satelitales de Landsat; además, se usaron técnicas en fotointerpretación, clasificación y

1 Bachiller. Centro Nacional de Alta Tecnología, Laboratorio PRIAS, San José, Costa Rica. Correo electrónico: cvargas@cenat.ac.cr

2 Magister Scientiae. Escuela de Ciencias Geográficas, Universidad Nacional de Costa Rica, Heredia, Costa Rica. Correo electrónico: ricardo.orozco.montoya@una.cr (Autor para correspondencia)

3 Licenciada. Secretaría Técnica Nacional Ambiental (SETENA), Ministerio de Ambiente y Energía, San José, Costa Rica. Correo electrónico: avahe08@gmail.com

4 Bachiller. Fundación Promotora de Vivienda (FUPROVI), Moravia, San José, Costa Rica. Correo electrónico: jaguilar@fuprovi.org
\end{abstract}


digitalización con Sistemas de Información Geográfica (SIG), determinando las manchas urbanas de cada país de la región para el periodo de estudio, lo que funciona como línea base para un análisis comparativo de cada ciudad capital utilizando elementos geográficos, políticos y algunos estudios afines al tema, siendo esta investigación un insumo para futuros estudios sobre análisis y planificación urbana, así como para el ordenamiento del territorio.

Palabras clave: Centroamérica; ciudades capitales; Landsat; sensores remotos; urbano.

\begin{abstract}
This paper presents the implementation of a methodology for determining the growth of urban sprawl in the capital cities of the Central American Region (CAR) during the period 1975-19952014. The objective of the investigation is to recreate the urban sprawl of the Central American capital cities throughout the studied years by means a methodology involving remote sensing and the implementation of various techniques for the processing and post-processing of Landsat satellite images. Additionally, photointerpretation, classification and GIS (Geographic Information Systems) digitalization techniques were used in determining the urban sprawls of each country for the period under consideration to provide a baseline for the comparative analysis of each capital city taking into account geopolitical elements and some related studies. (Se recomienda hacer pausa con punto para describir finalmente la utilidad del estudio). This study serves as input for future research on the analysis of urban planning as well as territorial planning.
\end{abstract}

Keywords: Central America; Capital cities; Landsat; Remote sensing; Urban.

\title{
Introducción
}

América latina y el Caribe es la región más urbanizada del mundo en desarrollo y se caracteriza por un crecimiento acelerado, ya que para 1950 los niveles de urbanización en esta región estaban muy por debajo de los registrados en países desarrollados de Europa, América del Norte y Oceanía, pero en menos de 40 años alcanzó los porcentajes urbanos europeos, debido principalmente a las migraciones desde áreas rurales a urbanas, generando un crecimiento urbano explosivo (Cunha y Rodríguez, 2009).

El proceso de urbanización en Latinoamérica tiene su origen desde la época colonial, marcada por la fundación de ciudades donde se daba el dominio primacial, heredado de economías extrovertidas que concentraban la riqueza en las antiguas capitales del imperio español, trasladando esta situación a las nuevas repúblicas latinoamericanas (Williams, 2004), de esta forma la corona española empezó a crear una "estrategia urbanamente centrada para la colonización” en Latinoamérica (Smith, 1991), lo cual repercutió en la designación de poblados, villas y ciudades como centros de control, por ejemplo, en Centroamérica ya para 1600 la mayoría de ciudades en Guatemala estaban fundadas, así como en El Salvador, 
Christian Vargas-Bolaños - Ricardo Orozco-Montoya - Annie Vargas-Hernández - Jairo Aguilar-Arias Methodology for determining the growth of urban sprawl in the capital

cities of the Central American region (1975-1995-2014)

siendo Nicaragua y Costa Rica las provincias con mayor área deshabitada (Smith, 1991). Basado en la centralidad heredada, desde ese momento y hasta la actualidad, las áreas rurales de Latinoamérica se han visto como un espacio complementario, dependiente en la mayoría de los casos de las ciudades y sobre todo de las grandes aglomeraciones que son vistas como los centros indiscutibles de control (Hidalgo y Borsdorf, 2009).

Uno de los principales procesos que ha conformado las ciudades latinoamericanas es el movimiento de la población del campo a la ciudad, el cual es considerado como uno de los factores que producen desequilibrios regionales en los países donde se han producido (Ospina, 2013). Este éxodo rural ha continuado y con ello la urbanización, llevando a la región a índices de un $80 \%$ de población urbana en la actualidad, solo superada por América del Norte (Cunha y Rodríguez, 2009).

Basado en lo anterior, para entender el esquema estructural actual de la ciudad latinoamericana, es importante la comprensión de su conformación desde la época colonial. De acuerdo con Hidalgo y Borsdorf (2009), la ciudad colonial fue catalogada como la ciudad compacta (1820); luego inicia una primera fase de urbanización que culmina en 1920 y desde ese momento inicia la segunda fase de urbanización, empujada por las migraciones campo-ciudad que se extienden hasta los años 80 , considerada como la ciudad polarizada. A partir de finales de los 80 y hasta la actualidad, las ciudades latinoamericanas son consideradas como ciudades fragmentadas o desconcentradas que han dado pie a la periurbanización.

El concepto de periurbanización es presentado por Cardoso y Ortiz (2012), como la integración de los antiguos núcleos rurales a las dinámicas metropolitanas como consecuencia de la suburbanización, la cual se refiere al surgimiento de periferias más o menos densas con conexión a la ciudad central. Es debido a esto que las ciudades latinoamericanas a partir de la década de los 90 evidencian una difusión y fragmentación hacia zonas periurbanas, generando una expansión de su mancha urbana.

El proceso anterior ha sido experimentado por las ciudades de la Región Centroamericana (RC), las cuales se convirtieron en las capitales de las repúblicas después de la independencia de 1821, localizadas la mayoría, en las zonas interiores de los territorios colonizados, a excepción de Panamá que fue construida desde el inicio a la orilla del mar (Lungo, 2001). El proceso económico de estas capitales inició con la economía 
cafetalera en la segunda mitad del siglo XIX y luego la instalación de las primeras industrias manufactureras iniciando el siglo XX, consolidando a San Salvador, San José y Managua como las principales ciudades centroamericanas, junto con Guatemala que fue la capital colonial y Panamá (Lungo, 2001).

Para 1970, los países centroamericanos tenían un $62 \%$ de su población residiendo en áreas rurales, lo cual cambió cuatro décadas después en el 2000, cuando Centroamérica dejó de ser mayoritariamente rural, pasando de un 44\% de habitantes ocupando áreas urbanas en 1990 a casi $50 \%$ en el 2000 y luego un 58.5\% en el 2010 (Urzúa, 2015). Para el año 2016 casi el 60\% de la población Centroamericana vivía en zonas urbanas, sin embargo, se espera que para las generaciones futuras siete de cada 10 habitantes se consoliden en las ciudades, siendo esto un equivalente a 700 000 nuevos residentes urbanos cada año, proyectando así un total de 25 millones de habitantes antes del 2050 (Banco Mundial, 2016).

Es importante indicar algunos datos que caracterizan la urbanización de los países centroamericanos según el Banco Mundial (2016), uno de ellos es que Centroamérica es la región con la tasa de urbanización más rápida del mundo, después de África; además el $81 \%$ del Producto Interno Bruto (PIB) se concentra en estas ciudades, generando una centralización y desigualdad con el resto del país. Se destaca que el 29\% de los ciudadanos de estas ciudades viven en asentamientos informales y el $75 \%$ de los activos se encuentran expuestos a riesgos de desastres.

Por otra parte, Augustin et al., (2018), indican que los países de Centroamérica concentran mayormente los desafíos más apremiantes de la región, experimentando en diversos grados, limitaciones para el crecimiento económico y la competitividad, falta de inclusión social y además destacan la exposición y vulnerabilidad de seis países de Centroamérica a los desastres, identificando la resiliencia como una importante prioridad de política. En cuanto a la inclusión social, la región Centroamericana sigue siendo testigo de la desigualdad de ingresos, la exclusión económica, falta de acceso a algunos servicios públicos básicos de calidad y alta tasa de delincuencia y violencia, a esto se suma la baja productividad, los bajos niveles de inversión y la falta de diversificación de las exportaciones (Augustin et al., 2018). 
Los datos anteriores evidencian las consecuencias del crecimiento espontáneo de las ciudades centroamericanas, ligado a una deficiente planificación que ha llevado al levantamiento de asentamientos informales en áreas más expuestas a efectos de desastres debido a la falta inclusión social, además de sistemas de transporte público ineficientes, e insuficiente infraestructura vial, recreativa y de servicios, así como contaminación por inadecuada disposición de residuos sólidos, uso poco sostenible del territorio y agudización de la vulnerabilidad a desastres (Orozco et al., 2015).

Dado lo anterior, surge la importancia de conocer el crecimiento y la extensión urbana de las capitales de Centroamérica; por ello el objetivo de la presente investigación es extraer la mancha urbana de las capitales centroamericanas en el periodo 1975-1995-2014, mediante una metodología de análisis de sensores remotos. Los resultados del presente trabajo pretenden ser una línea base para el análisis comparativo del crecimiento de estas ciudades en el periodo 1975-2014, de forma tal que el estudio sea un insumo para futuras investigaciones sobre la región que analicen las causas y consecuencias de esta expansión urbana.

El estudio se centra en mostrar la metodología empleada para la extracción de la mancha urbana del periodo de análisis, a través de la cual se emplearon diversas técnicas para el procesamiento y post-procesamiento de las imágenes satelitales de Landsat. Es de esta forma que los SIG y la utilización de imágenes satelitales, se convierten en una herramienta eficaz para el análisis urbano y su expansión.

\section{Área de estudio}

Para este estudio se utilizó la RC y sus ciudades capitales (Cuadro 1). La región está conformada por siete países: Guatemala, Belice, El Salvador, Honduras, Nicaragua, Costa Rica y Panamá (Figura 1), cuenta con una población de 47000000 millones de habitantes en una extensión de $522760 \mathrm{~km}^{2}$ (World Population, 2015). 
Christian Vargas-Bolaños - Ricardo Orozco-Montoya - Annie Vargas-Hernández - Jairo Aguilar-Arias Metodología para la determinación del crecimiento de la mancha urbana en las capitales de la región centroamericana (1975-1995-2014)

Cuadro 1: Características territoriales de países centroamericanos

\begin{tabular}{|c|c|c|c|c|}
\hline País & $\begin{array}{c}\begin{array}{c}\text { Población } \\
\text { Total }\end{array} \\
\end{array}$ & $\begin{array}{c}\text { Superficie } \\
\left(\mathrm{km}^{2}\right)\end{array}$ & $\begin{array}{c}\text { Densidad de } \\
\text { población }\left(\mathrm{hab} / \mathrm{km}^{2}\right)\end{array}$ & Ciudad capital \\
\hline Belice & 361000 & 23000 & 15.69 & Belmopán \\
\hline Guatemala & 15608000 & 109000 & 143.19 & Ciudad de Guatemala \\
\hline El Salvador & 6401000 & 21040 & 304.23 & San Salvador \\
\hline Honduras & 8309000 & 112100 & 74.12 & Tegucigalpa \\
\hline Nicaragua & 6198000 & 121430 & 51.04 & Managua \\
\hline Costa Rica & 4773000 & 51100 & 93.41 & San José \\
\hline Panamá & 3913000 & 74180 & 52.75 & Ciudad de Panamá \\
\hline
\end{tabular}

Fuente: Programa Estado de la Nación (2016).

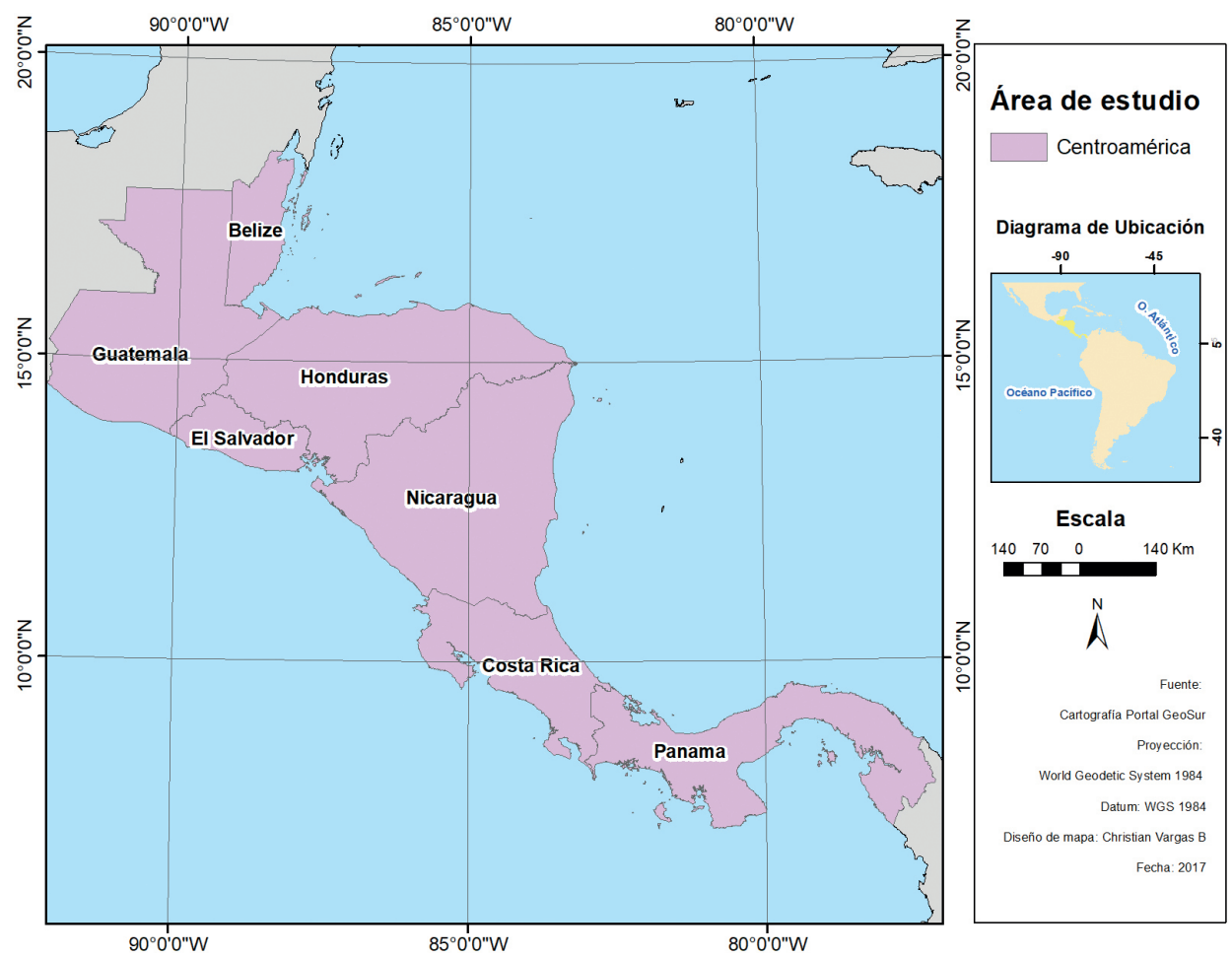

Figura 1: Área de estudio: Región Centroamericana (RC) 
El estudio considera el área metropolitana y la periferia, vistos estos como la mancha urbana de las ciudades capitales de los países de la RC. El área metropolitana fue definida como el área geográfica continua donde se forma una gran aglomeración que constituye un importante mercado de trabajo diversificado con relaciones de interdependencia entre los núcleos que la integran (Lahoz, 2010), la cual a su vez es definida por Moura y de F. Firkowski (2007), como la ciudad principal de aglomeraciones que se destacan no solo por los grados elevados de conentración poblacional y económica, sino por el desempeño de funciones complejas y diversificadas en el territorio, por la extensión espacial de las relaciones económicosociales y por la fuerza de centralidad que ejerce y trasciende a otros sitios.

Precisamente esta aglomeración está marcada por dos denominadores, según Serrano (2007): los formales y los funcionales. Los primeros suelen agrupar una serie de entidades urbanas con núcleos compactos y otras formas de poblamiento complementarias, donde existe una jerarquía urbana marcada tanto por sus volúmenes demográficos dispares, como por sus roles tradicionales, además a estos núcleos urbanos, se añaden, superponen y agregan en sus alrededores, proximidades y cercanías, otras formas de expansión. Los funcionales, corresponden a los flujos, tanto la infraestructura de transporte como los flujos inmateriales que de pronto no se advierten visualmente. De esta forma, partiendo de las definiciones anteriores es que se define el área metropolitana de cada ciudad capital de la RC.

Por su parte, la periferia se concibió como los extremos o márgenes geográficos en contraposición al centro. Es decir, periferia es el territorio externo de la ciudad formada por una franja en mayor o menor grado urbanizada, cuyas partes están localizadas a cierta distancia del centro y a las cuales éste extiende su acción (Arteaga, 2005). Es importante indicar que, para referirse a periferia en la actualidad, no se cuenta con un dato específico de distancia, si no, se sigue un patrón de dispersión con características residenciales en su mayoría (Orozco et al., 2015).

\section{Metodología}

El estudio es un acercamiento por parte del Informe del Estado de la Región para determinar cuáles han sido las capitales que han tenido un mayor aumento en su desarrollo urbanístico y cómo este se ha extendido por el territorio en el periodo 1975-2014. 
Tomando en cuenta que el interés del presente trabajo es mostrar el proceso metodológico empleado para la extracción de la mancha urbana de las capitales centroamericanas, se muestra la figura 2 que resume este proceso, el cual consiste en dos fases, la primera es el tratamiento de las imágenes satelitales del sensor Landsat 5, 7 y 8 mediante las etapas de pre y post procesamiento de las imágenes; y la segunda es la obtención de las coberturas vectoriales tipo shape, las cuales serán utilizadas en programas SIG para su análisis e interpretación.

El principal insumo para este trabajo fueron las imágenes Landsat, las cuales forman parte del Programa Landsat el cual tiene como objetivo la observación de la tierra por medio de satélites gestionados por la NASA y el Servicio Geológico de los Estados Unidos (USGS) (IGAC, 2013). Estas imágenes son gratuitas y en este proyecto se utilizaron los sensores: Landsat 2 para identificar la mancha urbana de los países de Centroamérica para el año 1975, el sensor Landsat 5 para el año 1995 y el sensor Landsat 8 para el año 2014 (Orozco et al., 2015). Los años elegidos responden a una cronología de 20 años, es decir, la importancia de su selección radica en la necesidad de observar los cambios cada 20 años en la mancha urbana, iniciando desde el 2014 como último año de análisis y desde ese hacia atrás para analizar el cambio.

\section{Fase I: Tratamiento de las imágenes Landsat}

\section{Preprocesamiento de las imágenes Landsat}

\section{Corrección Geométrica}

Estas correcciones se realizan debido al cambio en la direccionalidad del satélite y la captura de la información ocasionada por el sensor, las mismas están establecidas por la USGS que aplica una interpolación de convolución cúbica (Hantson et al., 2011; Chander et al., 2009). Para Chuvieco (2010), la corrección geométrica se genera debido al cambio en el posicionamiento de los pixeles que conforman la imagen, ya que al ser un formato digital, en este se aplican funciones numéricas (vecino más próximo, bilinear, convolución cúbica) que modifican la geometría; las mismas pueden ser verificadas en el metadato que acompaña las imágenes descargadas cuyo archivo es el MTL.txt; en él se lee la información del nombre del sensor, procesamiento que ha tenido la imagen y otra información importante. 
Christian Vargas-Bolaños - Ricardo Orozco-Montoya - Annie Vargas-Hernández - Jairo Aguilar-Arias Methodology for determining the growth of urban sprawl in the capital cities of the Central American region (1975-1995-2014)

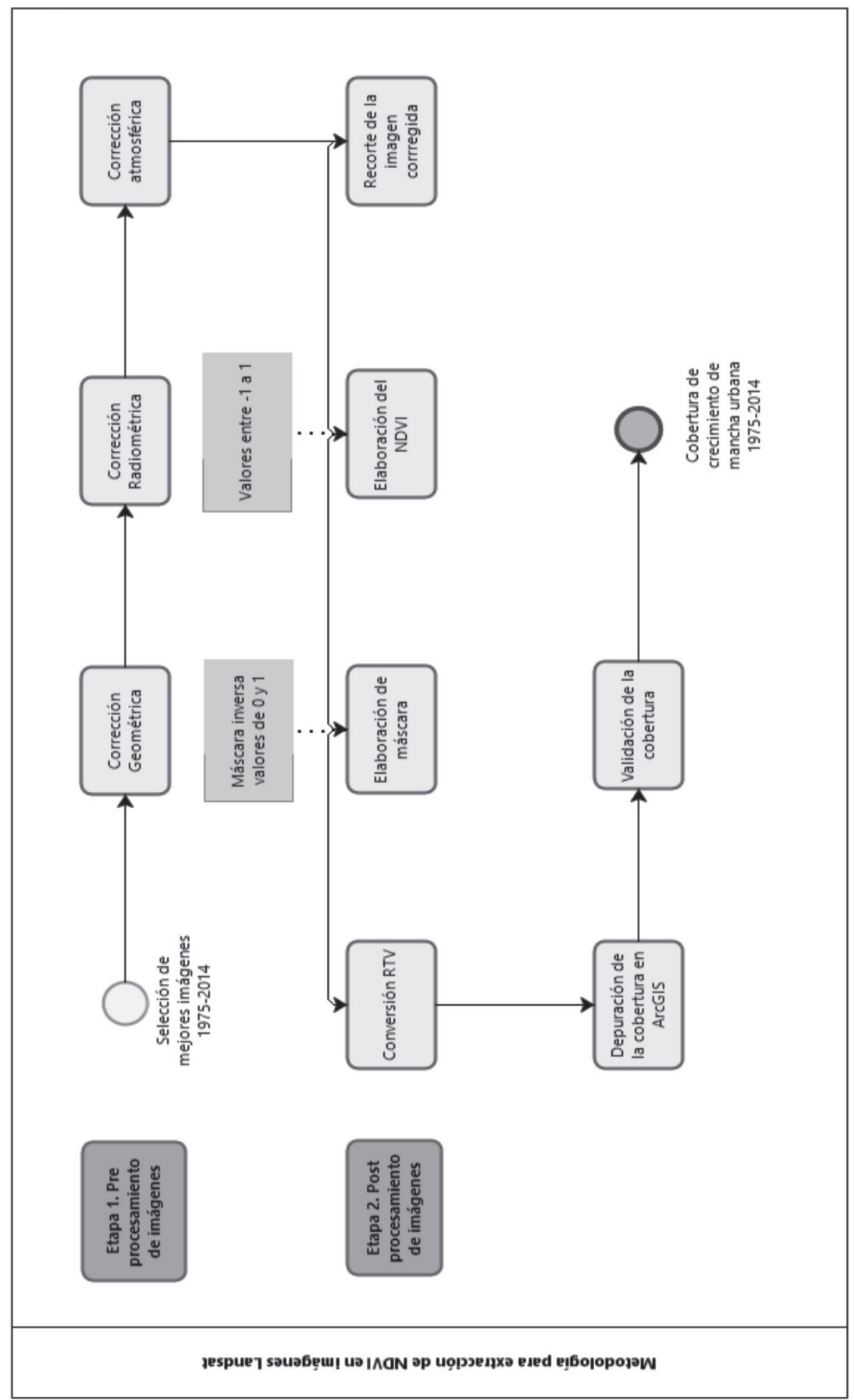

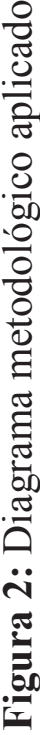




\section{Corrección Radiométrica}

Se entiende como la modificación de Números Digitales (ND), o valores que van en un rango de 0 a 255 en las imágenes satelitales cuyo valor sea de 8 bits, la información es almacenada por la intensidad de la radiación electromagnética (Kruse, 2004). El rango de los ND depende de cada sensor y de la cantidad de luz solar percibida en la toma de cada imagen, es por lo que los ND deben transformarse a una escala espectral normalizada (Edwards, 1998), convirtiendo los valores para cada una de las bandas del sensor a radiancia.

\section{Corrección Atmosférica}

Es un proceso que se aplica en imágenes satelitales posterior a la transformación de los valores de ND a valores de radiancia. Este proceso consiste en convertir la radiancia a valores de reflectividad en el techo de la atmósfera "Top of Atmosphere" (TOA), esto con la finalidad de eliminar el efecto de los aerosoles y la radiancia intrínseca que se introduce en el sensor (Aguilar et al., 2014; Brizuela et al., 2007); se utilizó el módulo FLASSH (Fast Line-of-sight Atmospheric Analysis of Spectral Hypercubes) del software ENVI 5.2.

\section{Postprocesamiento de las imágenes Landsat}

Posterior a las correcciones de las imágenes, se procedió a la realización del postprocesamiento de las imágenes Landsat. A continuación, se explica el proceso metodológico a seguir para el tratamiento de las imágenes:

\section{Recorte de la imagen}

La imagen Landsat abarca una extensión territorial mayor al área de estudio de interés, por lo que se realizó un recorte de la imagen con la herramienta ROI (Region of interest), extrayendo la mancha urbana de las ciudades capitales de los países Centroamericanos y parte de la periferia (buffer de $2.5 \mathrm{~km}$ ). Como referencia se utilizó la capa de mancha urbana del Programa GEOSUR, 2013.

\section{Elaboración del NDVI}

El NDVI (por sus siglas en inglés) es el índice de vegetación de diferencia normalizada. Este índice generalmente se utiliza para el análisis 
de la vegetación con valores de -1 a 1 , siendo -1 valores donde no hay presencia de vegetación, y 1 valores con presencia de esta. Sin embargo, en este estudio se utilizó de una manera inversa para la extracción de la mancha urbana. En este proceso, se realizó un ajuste a los parámetros para dar énfasis a la obtención de información de infraestructura urbana. Se calcula con la siguiente fórmula:

$$
\mathrm{NDVI}=\frac{I R-R}{I R+R}
$$

\section{Elaboración de la máscara}

La máscara se elaboró con el objetivo de separar la mancha urbana de todo aquello que no lo es. En este caso, se interpretó la máscara con valores de 0 y 1 , donde 0 representa valores no seleccionados para la interpretación, es decir, son valores que se desean excluir porque no representan un uso urbano, mientras que los valores de 1 son áreas seleccionadas y deseables.

Es así como con base en el NDVI generado con el programa ENVI, se aplicó una máscara inversa a partir de los valores extraídos de las imágenes, revirtiendo los valores que genera el NDVI, por lo tanto, los valores de 0 corresponden a áreas no urbanas como la vegetación y los valores de 1, representan toda la infraestructura urbana. Esta máscara de generó en formato raster.

\section{Fase II: Obtención de coberturas vectoriales}

\section{Conversión de raster a formato vectorial}

Posterior a la elaboración de la máscara que se obtuvo en formato raster, se procedió a la transformación de esta capa en formato vectorial.

\section{Depuración de la capa}

La depuración de la capa vectorial se ejecutó en el software ArcGIS 10.3, con la finalidad de limpiar la capa de rastros que no son de utilidad para el estudio. En este proceso se extrajo de la capa final: nubes, sombras de nubes, ríos, áreas verdes, así como aquellas coberturas que se consideraron innecesarias para cumplir con los objetivos de este proyecto. Es importante mencionar que se eliminaron todas las nubes y sombras de nubes que se encontraban dentro de la capa de la mancha urbana resultante, justificándose en el hecho de que no se tiene la certeza de la presencia de 
uso urbano en estas zonas. Además, no se utilizaron otras imágenes para completar el faltante de información en estas áreas.

\section{Validación}

La validación se realizó por medio de un análisis Random con el uso del software ENVI, este análisis es una clasificación supervisada que mejora la precisión en la clasificación mediante la aleatoriedad, resultando de este modo una validación que permite mayor exactitud en la imagen (Richards, 2013). Se debe aclarar que para este estudio no se realizó validación de campo.

\section{Análisis del cambio de la mancha urbana}

El análisis del cambio de la mancha urbana se llevó a cabo con el software ArcGis 10.3, para obtener la diferencia de crecimiento urbano por medio del álgebra de mapas. Esta herramienta tiene como función la sobreposición de las capas de mancha urbana, restándose entre ellas para obtener la diferencia de crecimiento, es decir, se resta el año más actual al que lo antecede.

\section{Resultados}

Los resultados muestran los productos obtenidos a partir de la metodología empleada, con la finalidad de que estos funcionen como insumo y línea base de futuras investigaciones que ahonden en el tema de la expansión urbana de las capitales centroamericanas.

Los resultados se traducen en siete mapas que contemplan las manchas urbanas de los países que conforman la RC. En cada uno de ellos se sobreponen las capas de los tres periodos trabajados, siendo la mancha urbana de color rojo el primer año de análisis, correspondiente al año de 1975, el color amarillo el año intermedio, es decir, 1995 y el color verde el año más reciente, representado por el año 2014.

Cada mapa de los diferentes países se mostrará a continuación, donde a su vez se explicará el proceso en cuanto a la selección de imágenes y la aplicación de la metodología anteriormente expuesta. 
Christian Vargas-Bolaños - Ricardo Orozco-Montoya - Annie Vargas-Hernández - Jairo Aguilar-Arias Methodology for determining the growth of urban sprawl in the capital

cities of the Central American region (1975-1995-2014)

\section{1). Managua, Nicaragua; períodos 1975, 1996, 2014}

Para el caso de la mancha urbana de Managua, Nicaragua; se trabajó con las imágenes del sensor Landsat 2, 5 y 8, que corresponden a los años 1975, 1996 y 2014 respectivamente (Figura 3).

La selección de las imágenes se basó en la escogencia de aquellas que tuvieran menor porcentaje de nubosidad sobre la mancha urbana de Managua. No obstante, algunas secciones en la cobertura urbana de 1975 y de 2014, como se observa en la figura 3, carecen de información debido a la nubosidad presente, por lo que se desconoce si existe o no cobertura urbana en esa zona, por ello se optó por no tomarlo en consideración dentro del resultado final de la capa.

Respecto a la mancha urbana de Managua, puede destacarse que esta limita al este con el Aeropuerto Internacional de Managua Augusto C. Sandino, y al norte con el lago de Managua, como se aprecia en la figura 3. La ciudad de Managua y el municipio como tal forman parte de la Región Metropolitana de Managua (RMM), la cual, tiene una extensión aproximada de $6197 \mathrm{~km}^{2}$, lo que representa un $4.8 \%$ del territorio nacional, con una población de un poco más de 2000000 de habitantes (Orozco et al., 2015).

La ciudad de Managua surge desde la colonia como el centro de poder político, administrativo y con claras relaciones con el resto del territorio, por lo cual, recibe el título de capital en la segunda mitad del siglo XIX (Delgado, 2012). La ciudad ha protagonizado distintas situaciones desde su conformación, siendo una de las más graves en 1972 cuando fue impactada por un terremoto de magnitud 6.2 grados, generando daños en toda la ciudad; además en el periodo 1979-1990 se da la revolución nicaragüense con el Frente Sandinista de Liberación Nacional (FSLN) que provoca fuertes flujos migratorios internos y fuera del país (Orozco et al., 2015). 


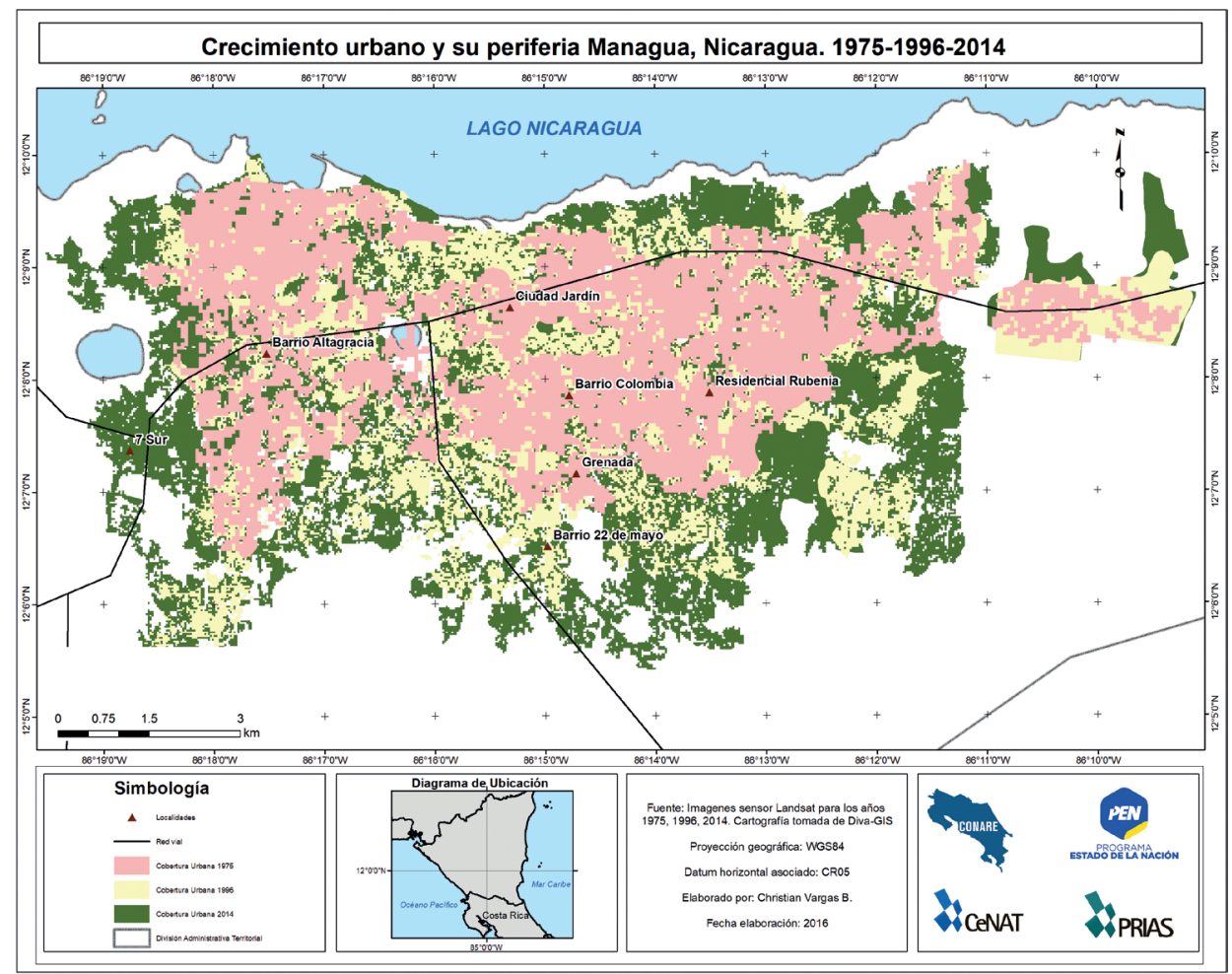

Figura 3. Comparación del crecimiento de la mancha urbana de Managua, Nicaragua, del periodo 1975, 1995, 2014.

Desde 1975 la mancha urbana de Managua inicia un proceso de conurbación con otros centros urbanos cercanos a la capital como Colonia El Periodista, Altamira y Rubenia; luego para 1995, el crecimiento se dirige hacia el este y sur de la capital, y finalmente para el 2014, su expansión se dirige hacia el sector oeste, constituyendo un proceso de periurbanización (Orozco et al., 2015). En la actualidad, la RMM involucra 30 municipios adyacentes con una conectividad importante, produciendo conurbaciones entre municipios como el eje de carretera a Masaya: Managua-Ticuantepe, en el oeste en la carretera hacia León: Managua-Ciudad Sandino, Managua-Mateare, hacia la carretea sur Managua-El Crucero y hacia la carretera norte: Managua-Tipitapa (Uribe et al., 2010). 
Christian Vargas-Bolaños - Ricardo Orozco-Montoya - Annie Vargas-Hernández - Jairo Aguilar-Arias Methodology for determining the growth of urban sprawl in the capital cities of the Central American region (1975-1995-2014)

\section{2). Belmopán, Belice; períodos 1984, 1995, 2014}

En la figura 4 se observa la mancha urbana de la ciudad de Belmopán, Belice. Debido a la cantidad de nubes presentes en el área de interés en la imagen del año 1975, se utilizó la imagen del año 1984, haciendo la aclaración de que a pesar de que el año de esta imagen es distinto, el sensor de captura de la imagen es el mismo: Landsat 2.

Igualmente, para las manchas urbanas siguientes se trabajó con los años 1995 y el 2014, puesto que las imágenes presentaban las condiciones óptimas para trabajar la mancha urbana en el área de interés (Figura 4).

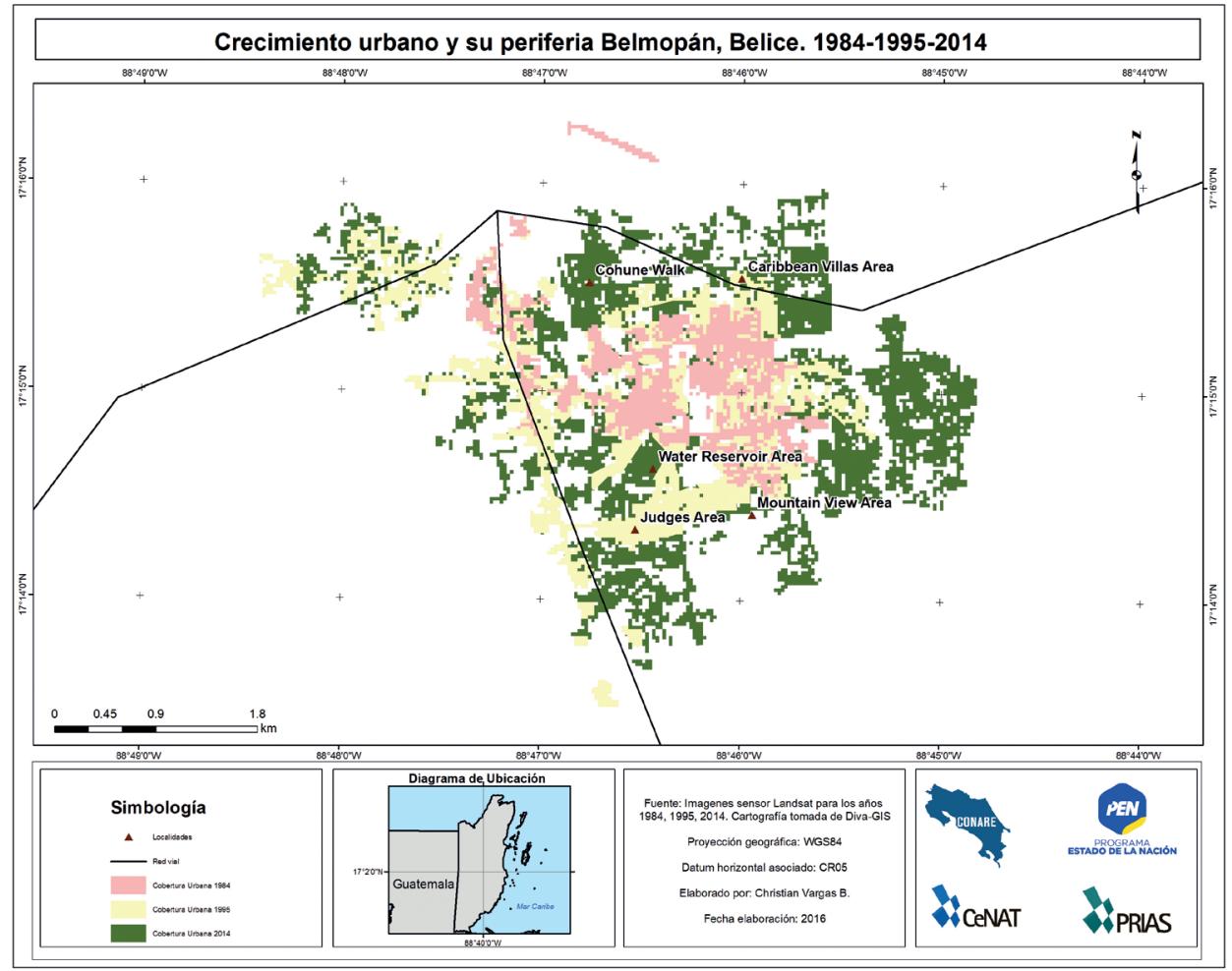

Figura 4. Comparación del crecimiento de la mancha urbana de Belmopán, Belice, del periodo 1984, 1995, 2014 
La ciudad de Belmopán es una de las capitales más jóvenes del continente americano, por lo tanto, su fortalecimiento ha sido menor al resto de las ciudades. Su fundación se dio en 1970, ya que la antigua capital beliceña, la ciudad de Belice, fue devastada por un huracán en 1969 debido a su localización en la costa del Caribe, es debido a lo anterior que se decide el traslado de la capital a Belmopán (Torres, 2008).

Belmopán fue fundada debido al crecimiento de su sector industrial, que para 1984 estaba conformada por 167 Ha localizadas alrededor de la red vial circundante. Para 1995, el crecimiento de la mancha urbana se da hacia el sur y oeste, generando un patrón de conurbación más visible hacia otros centros urbanos como Roaring Creek. Ya para el 2014 la expansión urbana de Belmopán es sorprendente, creciendo 4.5 veces más respecto al 2014 (Orozco et al., 2015).

\section{3). San Salvador, EI Salvador; períodos 1975, 1995, 2014}

La mancha urbana de San Salvador se aprecia en la figura 5. Los años de cobertura urbana corresponden a 1975, 1995 y 2014.

Las capas correspondientes a esta ciudad capital requirieron de una depuración cuidadosa, ya que San Salvador cuenta con límites naturales como el volcán de San Salvador y el Cerro San Jacinto que cuentan con una cobertura vegetal bastante considerable, por lo que posterior a la creación de la máscara se tuvieron que remover varios píxeles que no correspondían a cobertura urbana, dando como resultado las tres manchas urbanas expuestas en la figura 5.

La ciudad de San Salvador está situada en el centro del país y fue constituida durante la época republicana (1811-1935), luego de la década de 1940 empezó a extender su estructura reticular hacia la periferia, configurándose el Área Metropolitana de San Salvador (AMSS) entre 1945 y 1965 (Lungo, 1999). Es de esta forma como según la figura 5, puede observarse que para 1975, ya estaban conformados importantes centros urbanos como Nueva San Salvador (Santa Tecla), San Marcos, Mejicanos y Soyapango que estaban conectados con el AMSS por las vías de acceso, pero sin procesos de conurbación importantes. La situación anterior cambia para 1995, cuando se observa que dichos centros urbanos pasaron a formar parte de la mancha urbana de San Salvador, creciendo esta hacia todas direcciones (Orozco et al., 2015). 


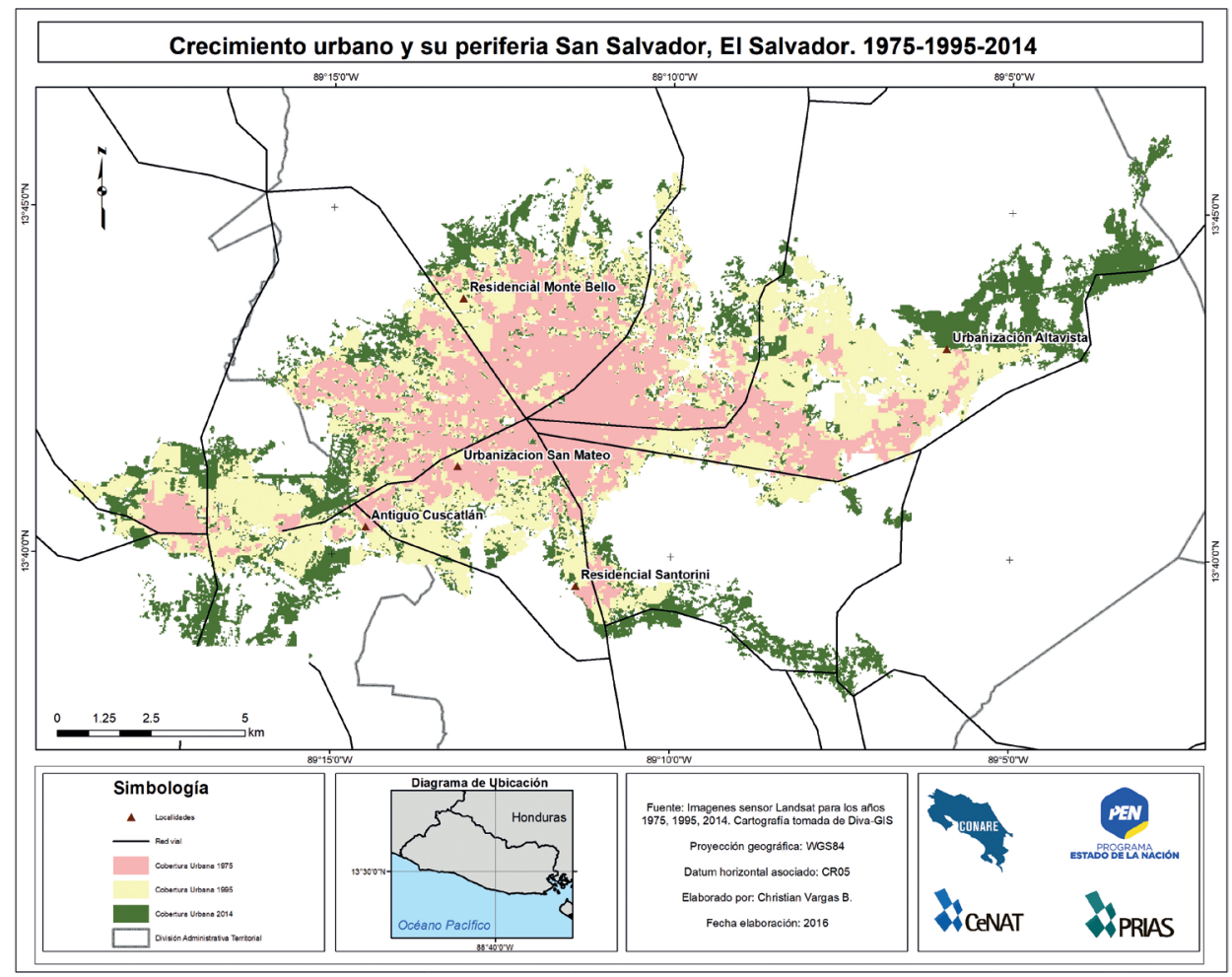

Figura 5. Comparación del crecimiento de la mancha urbana San Salvador, El Salvador del periodo 1975, 1995, 2014

Para el 2014, la mancha urbana de San Salvador es de aproximadamente $12400 \mathrm{Ha}$, evidenciando su crecimiento hacia la cercanía de áreas protegidas como el volcán de San Salvador al noroeste, el cerro San Jacinto al sureste y el lago llopango situado al este, los cuales a su vez se muestran como limitantes para la expansión de la mancha urbana hacia estos sectores (Orozco et al., 2015), sin embargo, la periurbanización se ha extendido hacia el sector norte y noreste conectando con el municipio de San Martín, y luego hacia el suroeste uniendo con Nuevo Cuscatlán y hacia el sureste con Santo Tomás.

Es importante indicar el proceso de periurbanización del AMSS, ya que sobresale el crecimiento de población de manera acelerada en los municipios y centros urbanos que conectan con el centro, pero el municipio de San Salvador como tal experimenta una tasa de decrecimiento respecto 
a los municipios colindantes, sin embargo, el empleo y la provisión de ciertos servicios se concentra en la AMSS, principalmente en San Salvador, Santa Tecla y Antigua Cuscatlán (Uribe et al., 2010), lo cual resalta la centralización y el proceso de fragmentación de la ciudad, la cual es vista como centro administrativo y laboral, relegando la residencia hacia las afueras de la ciudad y con ello fortaleciendo la periurbanización.

\section{4). Tegucigalpa, Honduras; períodos 1975, 1995, 2014}

Los años trabajados para la mancha urbana de Tegucigalpa fueron 1975, 1995 y 2014. Algunas secciones de la cobertura de 1975 carecen de información debido a la presencia de nubes en el área de interés. Para el año 1995, dichas secciones cuentan con información que permiten suponer que hace 20 años posiblemente sí había presencia de cobertura urbana en esa área, pero que no se puede asegurar. Lo anterior se termina de ratificar con la mancha urbana del 2014, como se aprecia en la figura 6 .

La ciudad de Tegucigalpa es denominada el Distrito Central (DC) y está conformada por dos ciudades gemelas, Tegucigalpa al este y Comayagüela al oeste, las cuales se fusionaron en 1938 mediante la conformación del Municipio del Distrito Central (MDC) (Orozco et al., 2015).

Para 1975, la mancha urbana de Tegucigalpa se caracterizó por ser compacta y pequeña con algunas conurbaciones hacia Comayagüela, Ciudad Nueva y San José de la Vega; luego para 1995 la mancha urbana se expande de manera gradual principalmente hacia el este y oeste; por último, para el 2014, sobresale una periurbanización mayor hacia todas direcciones y siguiendo el patrón de las principales vías de comunicación.

De acuerdo con Uribe et al., (2010), Tegucigalpa está rodeada de 13 municipios con los cuales se ha dado el proceso de conurbación, teniendo como límites físicos para su crecimiento las montañas El Picacho, El Piligüin y El Hatillo al noreste y el cerro Grande y Berrinche al noroeste, así como los ríos Guacerique, Grande y Chiquito al Suroeste. Es importante destacar que la ciudad es de topografía muy irregular, rodeada de montañas y con condiciones difíciles para su expansión, además posee terrenos susceptibles a deslizamientos debido a su formación geológica, pendiente y formas de construcción de la ciudad (Uribe et al., 2010).

La ciudad ha experimentado situaciones particulares que han marcado su desarrollo, una de ellas se dio en la década de 1950 cuando se dio una 
explosión demográfica por migraciones internas, lo que generó una severa crisis urbana, déficit habitacional y de servicios públicos que se mantiene hasta la actualidad (Uribe et al., 2010). Otra situación importante se da en 1998, cuando el huracán Mitch devastó la capital hondureña, lo cual evidenció la falta de planificación y construcción en áreas no óptimas.

\section{5). Ciudad de Guatemala, Guatemala; períodos 1975, 1995, 2014}

Para Ciudad de Guatemala, la mancha urbana se elaboró con las imágenes satelitales de los años 1975, 1995 y 2014, coberturas que sirvieron de insumo para la confección de la figura 7.

Algunas secciones de las diferentes coberturas urbanas tenían presencia de nubes, por lo que en la depuración se descarta dicha información como parte de la mancha urbana de Ciudad de Guatemala, ya que se desconoce la existencia de uso urbano en la zona cubierta por nubosidad.

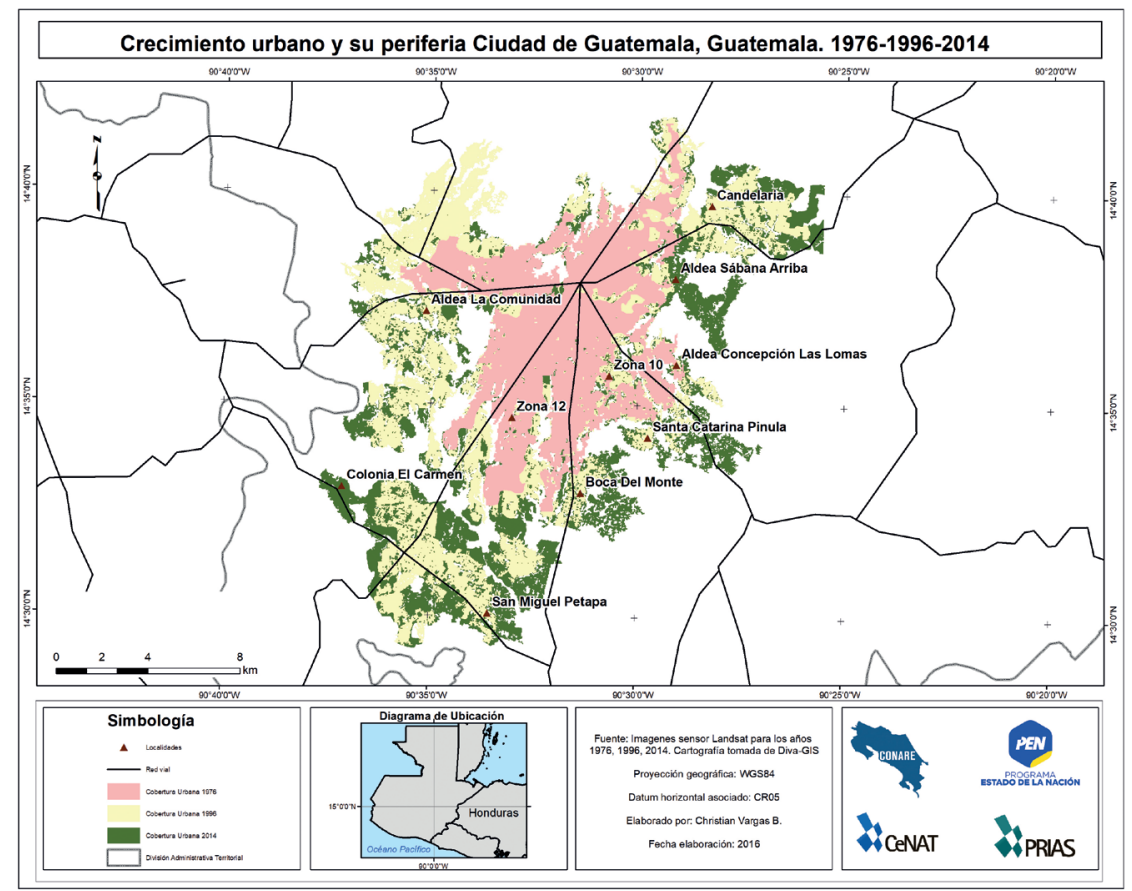

Figura 7. Comparación del crecimiento de la mancha urbana de Ciudad de Guatemala, Guatemala, del periodo 1975, 1995, 2014. 
La ciudad de Guatemala ha tenido un proceso de metropolización desde 1950 cuando el Área Metropolitana de la Ciudad de Guatemala (AMCG) comienza a rebasar los límites jurisdiccionales del municipio de Guatemala, alcanzando municipios periféricos por medio de la conurbación y migraciones internas entre municipios, por lo cual, actualmente se considera todo el departamento como la región metropolitana del país (Uribe et al., 2010).

Desde 1975, puede observarse que la mancha urbana de la ciudad de Guatemala tiene un proceso de conurbación hacia otros municipios, que luego para 1995, este se consolida hasta conectar dentro de la mancha urbana a municipios como Colonia Santa Marta, Candelaria, Santa Catarina Pinula y Villa Nueva, creciendo de esta forma hacia todas direcciones, y observándose un crecimiento acelerado en 20 años (Figura 7). Luego para el 2014, se observa que el crecimiento no es tan notorio, y este se intensifica al noreste y suroeste.

Es importante indicar que la Ciudad de Guatemala ha experimentado una serie de situaciones ligadas a diversos factores, uno de los más notorios, es que la capital se ha trasladado en tres ocasiones debido a terremotos que han devastado la ciudad, de lo cual la actual capital no se libró, ya que en 1976 se dio uno que provocó daños y pérdidas considerables. Otro factor importante, fue la guerra civil entre 1960-1996 que provocó la migración de gran cantidad de personas hacia la capital (Rivadeneira, 2001).

De acuerdo con Uribe et al., (2010), la configuración territorial metropolitana de la Ciudad de Guatemala tiene una estructura de centros asimétrica y desequilibrada con una constante macrocefalia de la ciudad dentro de los centros urbanos circundantes. Para el 2010, la población de Ciudad de Guatemala superó lo tres millones de habitantes, concentrando al $22 \%$ de la población total del país en este territorio con una densidad de 1.42 habitantes por $\mathrm{km}^{2}$, lo cual representa 10 veces más del promedio nacional (Uribe et al., 2010).

\section{6), Ciudad de Panamá, Panamá; períodos 1979, 1997, 2015}

En el caso de Ciudad de Panamá, la mancha urbana se trabajó con el año 1979 debido al significante porcentaje de nubes que contenía la imagen de 1975; el año intermedio se trabajó con la imagen de 1997 ya que fue la única disponible en el área para ese periodo específico, y la imagen para 
el periodo reciente corresponde al 2015, justificándose su elección por el hecho de que cuenta con información más actualizada. Se tiene como resultado final tres capas que representan el incremento de la mancha urbana de Ciudad de Panamá, tal y como se aprecia en la figura 8.

La expansión de la mancha urbana de la ciudad de Panamá claramente ha sido provocada en gran parte por el Canal de Panamá y todo el desarrollo que ha llevado este a la ciudad, este inició a comienzos del siglo XX y para 1913 se estableció un límite de crecimiento urbano a la ciudad, que luego con la construcción de la carretera transístmica en 1942, se inicia una conurbación más agresiva hacia el sector norte (Uribe et al., 2010).

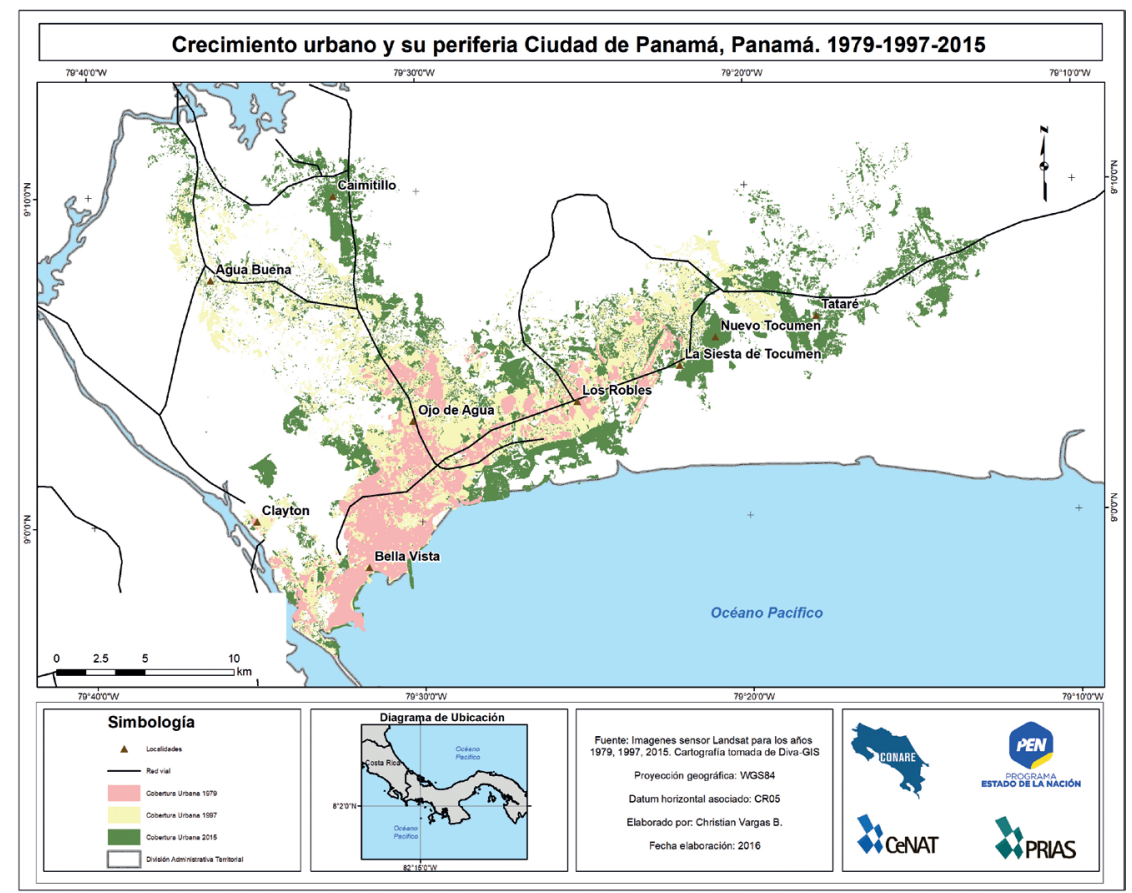

Figura 8. Comparación del crecimiento de la mancha urbana de Ciudad de Panamá, Panamá, del periodo 1979, 1997, 2015.

La mancha urbana de la Ciudad de Panamá en 1979 tenía un estrato urbano ya consolidado y algunos centros urbanos de la periferia comenzaban a mostrar conectividad con Ciudad de Panamá. Además, el Canal de Panamá, la costa, el Cerro Ancón y el Parque Natural Metropolitano, 
marcan las nuevas líneas de crecimiento de la ciudad. Para 1997 la mancha urbana se extendió hacia el norte y el este principalmente, evidenciando un proceso de conurbación con los centros urbanos de Tocumen, Alcalde Díaz y Paso Real. Para el 2015, se aprecia el estrato de la mancha urbana, donde Chilibre empieza a unificarse con Alcalde Díaz, debido al crecimiento urbano en dirección norte y noroeste. Además, hacia el sector este, Tocumen y Pacora también presentan indicios de conurbación (Orozco et al., 2015). Por otro lado, la mancha urbana de Ciudad Panamá presenta características de desarrollo lineal en su periferia, lo que evidencia la influencia de la red vial en la periurbanización.

El Área Metropolitana de Panamá (AMP) ha sido dividida por Uribe et al., (2010) en cinco zonas: casco central que contiene tres subzonas, casco viejo, centro e intermedia; área del canal, en el corregimiento de Ancón; periferia norte, que incluye al distrito de San Miguelito, y los corregimientos de Las Cumbres y Chilibre en el distrito de Panamá; periferia este, incluyendo los corregimientos Juan Díaz, Tocumen y Pacora del distrito de Panamá; y la periferia oeste, que está conformada por el distrito de Arraiján y los corregimientos más urbanizados del distrito La Chorrera, como barrio Balboa, barrio Colón, Guadalupe, El Coco, playa Leona y Puerto Caimito.

\section{7). San José, Costa Rica; períodos 1975, 1996, 2014}

En cuanto al resultado obtenido para la mancha urbana de San José, esta se puede observar en la figura 9. La cobertura urbana corresponde a los años 1975, 1996 y 2014. No se incluye la ciudad de Cartago debido a que los cerros de Ochomogo y la zona protectora Cerros de La Carpintera, han limitado la conurbación hacia el este de la capital, sin embargo, a lo largo de la autopista Florencio del Castillo que comunica San José con Cartago, se han ubicado cada vez más obras de desarrollo urbano.

Esta ciudad requirió de un proceso de depuración meticuloso, debido a la presencia de varios parches de cobertura vegetal dentro de la mancha urbana resultante, por lo que fue necesario extraer dicha información que no era de interés para este trabajo. 


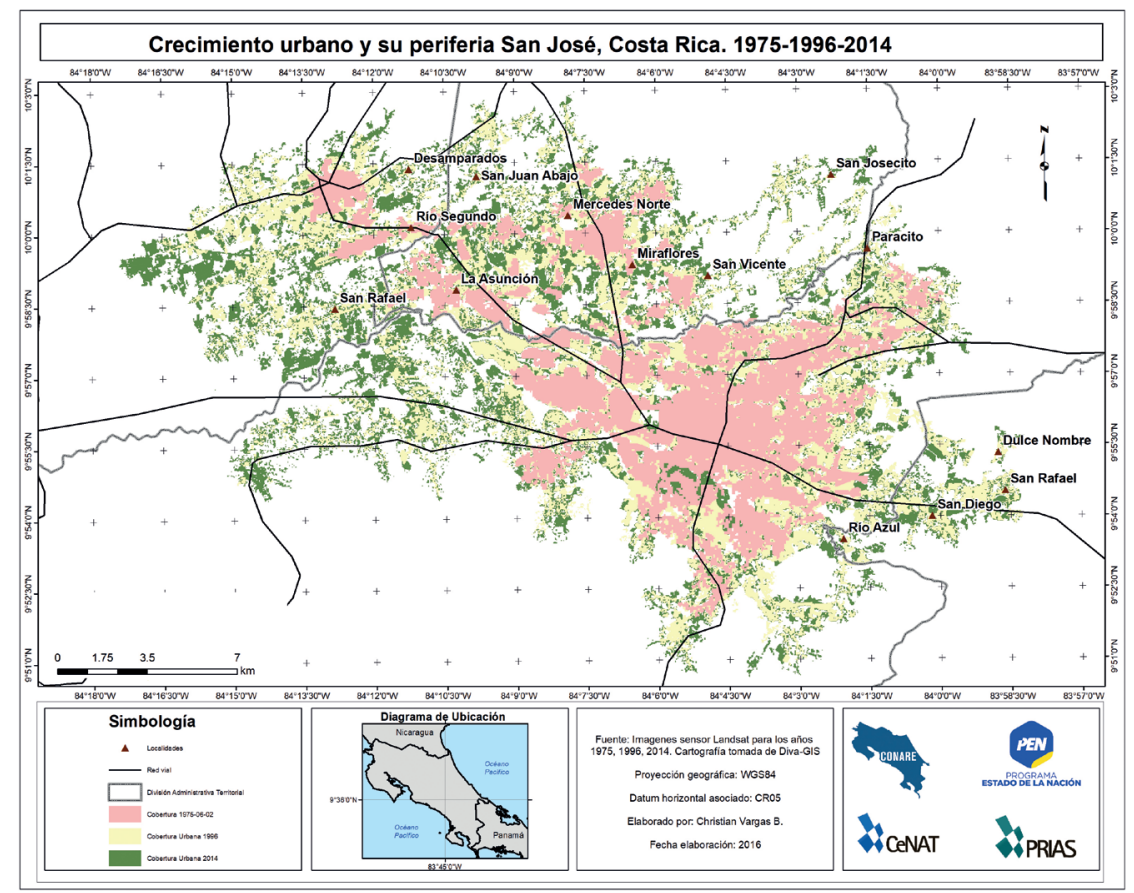

Figura 9. Comparación del crecimiento de la mancha urbana de San José, Costa Rica, del periodo 1975, 1996, 2014.

La mancha urbana de San José se ha convertido en una superficie homogénea que involucra a tres ciudades importantes: Alajuela, Heredia y San José, las cuales han crecido desde sus cascos urbanos y han logrado absorbes otros pequeños centros hasta conectarse de manera conjunta con la capital (Pujol y Pérez, 2012).

Para 1975 ya estaban conformadas las ciudades de Alajuela, Heredia y San José. Puede observarse que las tres ciudades se encontraban separadas, y para el caso específico de Alajuela y Heredia, se aprecia principalmente su casco urbano y unas pocas manchas urbanas siguiendo la ruta nacional $\mathrm{N}^{\circ} 3$ que comunica a ambas ciudades (Figura 9). Para el año 1996, se evidencia el crecimiento de las ciudades de San José, Alajuela y Heredia, las cuales para este año presentan una expansión importante que no se concentró solo en los centros urbanos, sino en otros centros que fueron habitados debido al proceso de conurbación que se llevó a cabo, como es el caso de La Guácima, San Isidro y Santa Ana. Se muestra, una mancha 
urbana en constante crecimiento principalmente al sur y este de San José, en el sector de Aserrí, Tres Ríos y Mata de Plátano (Orozco et al., 2015).

En el 2014, se observa un aumento de la mancha urbana principalmente en la parte sur y oeste de San José, repitiendo el patrón de crecimiento desde el año 1975, y además se aprecia un crecimiento al norte de las ciudades de Alajuela y Heredia. Tanto Tres Ríos, Santa Ana, Aserrí, Mata de Plátano y La Guácima; se consolidan como centros urbanos importantes en este último año de estudio.

De acuerdo con Jiménez (2017), en la Gran Área Metropolitana (GAM) conformada por las ciudades de San José, Alajuela, Heredia y Cartago, habita casi el $53 \%$ de la población total del país en apenas el $3.8 \%$ del territorio nacional. Las cuatro ciudades principales se han conurbado y han generado que otras cabeceras cantonales ubicadas dentro de la GAM tengan en algunos casos especialización de actividades, como Montes de Oca, Escazú o Curridabat. Además, la periurbanización, ha llevado que otros centros urbanos más pequeños fuera del anillo de contención urbana se empiecen a desarrollar de manera acelerada como San Pedro de Poás, San Rafael de Heredia y Oreamuno de Cartago. Es así como la GAM se ha desarrollado como un sistema polinuclear desconcentrado que continúa transformando el suelo rural en urbano sin tener certeza sobre sus límites (Jiménez, 2017).

\section{8). Comparación de las manchas urbanas de la Región Centroamericana}

Con los resultados obtenidos por cada país de la $\mathrm{RC}$, se procedió a hacer una comparación entre las diferentes manchas urbanas, como un insumo para futuras investigaciones que se puedan desprender de este trabajo (Figura 10). Por su parte, la figura 11 muestra el aproximado del crecimiento de las manchas urbanas de los siete países de la RC. Los datos obtenidos se expresan en hectáreas (Ha) y permiten comprender el comportamiento en cuanto al aumento de la cobertura urbana entre los periodos trabajados por país, así como analizar o comparar dicho crecimiento entre países. 
Christian Vargas-Bolaños - Ricardo Orozco-Montoya - Annie Vargas-Hernández - Jairo Aguilar-Arias Methodology for determining the growth of urban sprawl in the capital

cities of the Central American region (1975-1995-2014)
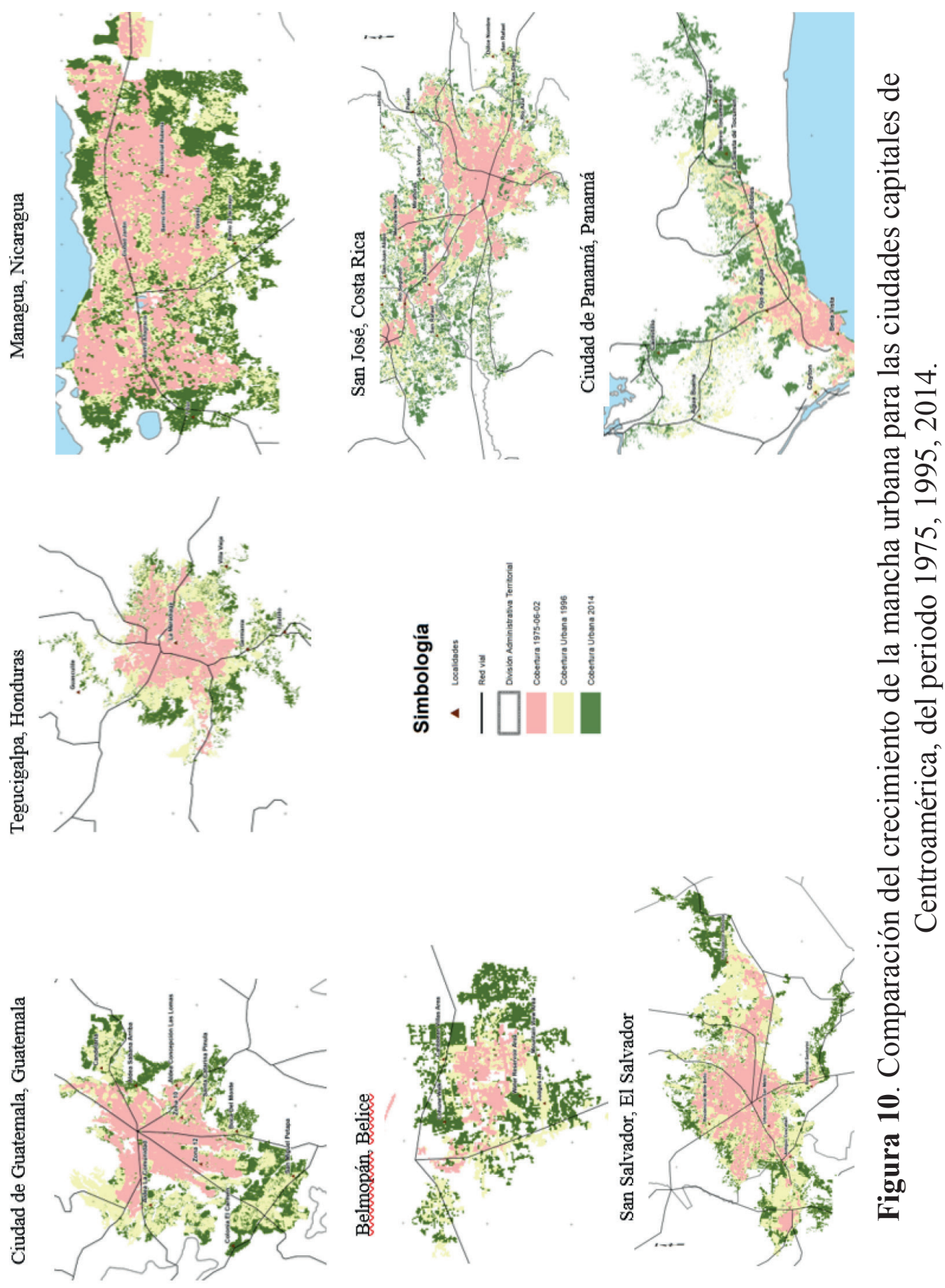


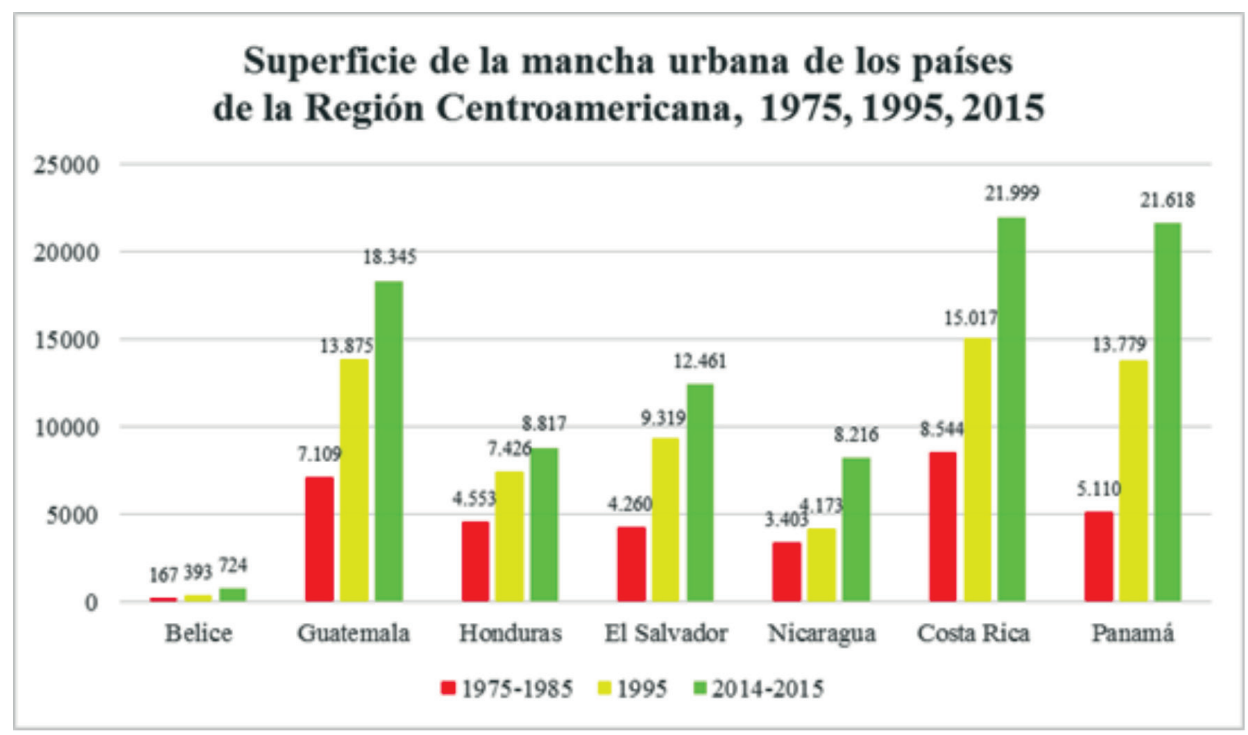

Figura 11. Superficie de la mancha urbana de los países de la Región Centroamericana.

La mancha urbana de San José, Costa Rica es la que predomina en los tres años trabajados, mientras que Belmopán, Belice se encuentra en la última posición.

Las manchas urbanas de mayor crecimiento en el periodo de estudio fueron para los países de Panamá y Costa Rica, debido principalmente a su orografía plana (32.2\% y 28.4\% respectivamente), seguido por El Salvador con $22.7 \%$ de crecimiento. En el caso de Nicaragua, Guatemala y Honduras, el proceso de crecimiento de población urbana fue más lento, oscilando entre $9.6 \%$ y $15.4 \%$. Belice es un caso excepcional, ya que además de ser el país más pequeño con menor población de la región, presentó una disminución de la población urbana (-1.5\%), lo anterior de acuerdo con datos del Programa Estado de la Nación (2013; 2014).

De acuerdo con los datos de la figura 11, la ciudad de Panamá pasó de tener 5110 hectáreas en 1975 a 21618 hectáreas en el 2014, lo que implica un crecimiento del área de 323\% (16 508 ha). En el caso de Belmopán, su mancha urbana tuvo una fuerte expansión (334\%) durante el periodo analizado, lo cual contrasta con la disminución en la proporción de población urbana a nivel nacional, lo que podría evidenciar que el crecimiento 
urbano del país se concentró en la ciudad capital (Orozco et al., 2015). Por su parte, en El Salvador, Guatemala y Nicaragua, el crecimiento de la mancha en el periodo osciló entre 193\% y 141\%.

En 1975, la Ciudad de Guatemala ocupaba el segundo lugar, después de San José en cuanto a superficie de mancha urbana, seguido por Ciudad de Panamá en tercer lugar, Tegucigalpa en el cuarto puesto y San Salvador en la quinta posición. Para 1995 tanto la mancha urbana de San José, Ciudad de Guatemala y Ciudad de Panamá mantienen las posiciones que ocupaban en el periodo previo. Sin embargo, San Salvador subió al cuarto puesto y Tegucigalpa pasó al quinto lugar (Orozco et al., 2015).

Finalmente, en el periodo 2014-2015, la mancha urbana de Ciudad de Panamá se ubica como la segunda de mayor superficie, muy similar a la de San José y es seguida por Ciudad de Guatemala en el tercer lugar. Mientras que San Salvador y Tegucigalpa ocupan las mismas posiciones que en el periodo previo.

\section{Discusión}

El análisis espacial mediante el uso de los SIG ha permitido que este estudio proyecte una perspectiva sobre el crecimiento de la mancha urbana para las ciudades capitales de la RC, y para medir este crecimiento se utilizaron imágenes de satélite del sensor Landsat 5, 7 y 8. Justificando su uso, ya que la familia de este satélite se mantiene capturando información desde los años 70, siendo este sensor considerado como el proyecto de mayor longevidad en la observación de la Tierra a través de imágenes multiespectrales.

Es basado en lo anterior que la aplicación de la metodología evidencia que, a nivel regional, el área de las manchas urbanas casi se triplicó en los últimos 40 años, pasando de 33146 hectáreas en 1975 a 92180 en el año 2014. Dado el alto crecimiento de la Ciudad de Panamá, su peso relativo pasó de $15 \%$ a $23 \%$, junto con la ciudad de San José figuran el $47 \%$ e incluyendo la Ciudad de Guatemala representan el 67\% del área metropolitana total de la región (Orozco et al., 2015). Esta extensión de la mancha urbana se da por un proceso de periurbanización que se ha consolidado en los últimos años, uniendo centros urbanos aislados a la dinámica territorial de las capitales. 
La periurbanización en latinoamericana toma importancia a partir de la década de 1990, promoviendo la expansión territorial, es de esta forma como las áreas periféricas se expanden en la $\mathrm{RC}$ en respuesta a las siguientes funciones de acuerdo con Cardoso y Ortiz (2012): a) función residencial: atiende a las necesidades habitacionales de distintas clases sociales; b) función de abastecimiento: distribuye para la ciudad y para el campo productos y servicios (energía, agua potable, salud, transporte, aeropuertos, entre otros); c) función industrial: necesidad de espacio, bajo costo del suelo y proximidad a rutas clave, lo que favorece las instalaciones industriales en el área periurbana; d) función social: el periurbano ofrece a la población áreas de esparcimiento y recreación, así como áreas educativas; e) función ecológica: puede tener la función de equilibrio de sistemas naturales de una región.

Específicamente las ciudades capitales de la RC son de especial interés, principalmente porque la región cuenta con la tasa de urbanización más rápida del mundo (Banco Mundial, 2016), por lo que Lungo (2000) las reconoce como ciudades grandes en países pequeños, lo que podría acarrear una serie de problemáticas que se dan en las grandes urbes latinoamericanas; una de ellas la manifiesta Lungo (2001), en cuanto a la ocurrencia de eventos de desastre en las capitales centroamericanas, poniendo en manifiesto su vulnerabilidad de acuerdo con su ubicación y al proceso de construcción y conurbación que han vivido, por ejemplo, Lungo (2001) analiza la situación de San Salvador, San José y Ciudad de Panamá, donde las dos primeras se ubican en ámbitos territoriales similares, como valles intermontanos afectados por erupciones volcánicas y sismos frecuentes, tierras de alta fertilidad y biodiversidad, cuya expansión territorial ha provocado la disminución y erradicación de tierras aptas para la agricultura y de riqueza natural, lo que ha llevado a la expansión urbana hasta áreas más susceptibles a deslizamientos u otras amenazas, mientras que Panamá tiene sus amenazas ligadas a eventos costeros.

Basado en lo anterior y en el proceso constructivo de las capitales de los países de la RC, puede determinarse que seis de ellas (Ciudad de Guatemala, San Salvador, Tegucigalpa, Managua, San José y Ciudad de Panamá) se encuentran ubicadas en áreas donde los límites a su expansión territorial están dados por límites físicos, como áreas montañosas, volcanes, lagos, zonas protegidas o el mar, sin embargo, algunas de estas áreas se encuentran con procesos de periurbanización hacia los sectores montañosos principalmente, asentándose población en áreas de riesgo. 
Es importante indicar que los anteriores son hallazgos generales obtenidos del análisis de las manchas urbanas de las capitales centroamericanas, no obstante, el objetivo de este trabajo no consiste en determinar las razones o condiciones que han propiciado el crecimiento más rápido o más lento de una capital, sin embargo, se deja el insumo para que se incentiven nuevos estudios.

Por su parte, la metodología utilizada, que es el principal tema de análisis de este trabajo, tiene como ventaja que puede ser replicada en otras áreas urbanas del mundo y realizarse una comparación entre manchas urbanas de distintos continentes, debido a que las imágenes Landsat, como principal insumo, están disponibles para otras regiones. Además, la metodología utilizada podría aplicarse a otros temas no urbanos, por ejemplo, en vez de extraer la mancha urbana, podrían extraerse los parches de bosque en un corredor biológico o en una cuenca hidrográfica, también las zonas verdes en una ciudad o en un municipio, entre otros.

\section{Conclusiones}

La metodología aplicada permitió obtener el resultado esperado de la investigación, respecto a la comparación en el crecimiento de la mancha urbana de cada capital de la RC, siendo el índice de vegetación de diferencia normalizada, clave para la obtención de la mancha urbana. Además, la metodología es aplicable en otras temáticas no solo urbanas, sino ambientales.

El estudio aporta resultados en las capas vectoriales, las cuales podrán ser utilizadas por los investigadores y público en general; ya que no existía este tipo de información de manera accesible.

Las capitales de los países de la RC presentan un crecimiento notorio entre 1975 y 2014, evidenciándose la periurbanización en la mancha urbana analizada para la década de 1990, la cual se consolida y aumenta para la mancha analizada en el 2014.

El área total de las manchas urbanas configuradas por las ciudades capitales y las áreas periféricas de la región casi se triplicó en los últimos cuarenta años, pasando de 33146 hectáreas en 1975, a 92180 en 2014.

El proceso de expansión urbana se ha dado de manera distinta en los países de un periodo a otro. Las mayores tasas de crecimiento fueron las de Belice y Panamá (superiores al 7 \% anual), seguidos por El Salvador (5.51 
\%), Guatemala y Costa Rica (4.85\%). No obstante, en todos los países, excepto en Nicaragua, las tasas de crecimiento fueron mayores en el primer periodo (1975-1995) que en el segundo (1995-2014).

Las manchas urbanas de los países del sur de América Central (Costa Rica y Panamá) son las que han crecido más rápidamente de la RC en todos los periodos de análisis, a excepción de 1995 cuando la Ciudad de Guatemala creció mínimamente más que la ciudad de Panamá. Es así como Panamá y Costa Rica, siendo países pequeños y menos poblados, presentan el mayor incremento de mancha urbana, correspondiente al 32.2 $\%$ y $28.4 \%$, respectivamente.

Es importante considerar las coberturas a extraer de las imágenes de satélite, ya que, por su tamaño de píxel, en este caso 30 metros, se dificulta realizar la adecuada interpretación de la información, se sugiere trabajar con imágenes de mayor resolución ( 5 metros o menos) de ser necesario.

Considerar el trabajo de campo para la toma de datos, ya que al tratarse de un estudio a nivel regional existen áreas donde no es posible identificar la clase de uso/cobertura que existió en los periodos iniciales 1975-1995.

\section{Agradecimientos}

Al señor Alberto Mora, Coordinador del Informe del Estado de la Nación, Programa Estado de la Nación (PEN) del Consejo Nacional de Rectores (CONARE) en Costa Rica, por toda la colaboración brindada para conseguir la información pertinente y financiamiento para el desarrollo de este trabajo tan importante a nivel de la Región.

\section{Referencias}

Aguilar, H., Mora, R. \& Vargas, C. (2014). Metodología para la corrección atmosférica de imágenes ASTER, RapidEye, Spot 2 y Landsat 8 con el módulo FLAASH del software ENVI. Revista Geográfica de América Central, 53, 39-59.

Arteaga, I. (2005). De periferia a ciudad consolidada: Estrategias para la transformación de zonas urbanas marginales. Bitácora Urbano/ territorial, 9 (1), 98-111. Recuperado de http://www.redalyc.org/ pdf/748/74800909.pdf 
Christian Vargas-Bolaños - Ricardo Orozco-Montoya - Annie Vargas-Hernández - Jairo Aguilar-Arias Methodology for determining the growth of urban sprawl in the capital

cities of the Central American region (1975-1995-2014)

Augustin, M., Acero, J., Aguilera, A. \& García, M. E.d. (2018). Estudio de la urbanización en Centroamérica: Oportunidades de una Centroamérica urbana. Washington, DC: Banco Mundial. doi:10.1596/978-1-4648-1220-0.

Brizuela, A. B., Aguirre, C.A, Velasco, I. (2007). Aplicación de métodos de corrección atmosférica de datos Landsat 5 para análisis multitemporal. Recuperado de http://www.aet.org.es/congresos/xii/arg27.pdf: junio 2015

Banco Mundial. (2016). Estudio de la Urbanización en Centroamérica: Oportunidades de una Centroamérica Urbana. Recuperado de: http://documents.worldbank.org/curated/en/406571468196193946/ pdf/106268-REVISED-SPANISH-PUBLIC-P152713-CentralAmerica-Urbanization-Review-Final-Output-SPANISH-2.pdf

Cardoso, A. \& Ortíz, P. (2012). Periurbanización, segregación social y fragmentación territorial. Encuentro de Geógrafos de América Latina 12. Recuperado de: http://observatoriogeograficoamericalatina. org.mx/egal12/Geografiasocioeconomica/Geografiaurbana/255.pdf

Chander, G., Markham, B. L. \& Helder, D. L. (2009). Summary of current radiometric calibration coefficients for Landsat MSS, TM, ETM+, and EO-1 ALI sensors. Remote sensing of environment 113, 893-903.

Chuvieco, E. (2010). Teledetección ambiental: La observación de la Tierra desde el espacio. Barcelona, España: Editorial Planeta, S.A. Primera edición.

Cunha, J. M. \& Rodríguez, J. (2009). Crecimiento urbano y movilidad en América Latina. Revista Latinoamericana de Población, 3 (4-5), 27-64.

Delgado, H. (2012). La Región Metropolitana de Managua: Temas claves para el ordenamiento territorial. Tesis de Máster en Desarrollo Urbano y Territorial. Universidad de Catalunya, España.

Edwards, A. J. (1998). Lesson 3: Radiometric correction of satellite images: when and why radiometric correction is necessary. Recuperado de http://www.ncl.ac.uk/tcmweb/bilko/module7/lesson3.pdf: junio 2015

Hantson, S., Chuvieco, E., Pons, X., Domingo, C., Cea, C., Moré, G., Cristóbal, J., Peces, J.J., \& Tejeiro, J.A. (2011). Cadena de preprocesamiento estándar para las imágenes Landsat del Plan Nacional de Teledetección. Revista de Teledetección, (36), 51-61. 
Christian Vargas-Bolaños - Ricardo Orozco-Montoya - Annie Vargas-Hernández - Jairo Aguilar-Arias Metodología para la determinación del crecimiento de la mancha urbana en las capitales de la región centroamericana (1975-1995-2014)

Hidalgo, R \& Borsdorf, A. (2009). El crecimiento urbano en Europa: Conceptos, tendencias y marco comparativo para el área metropolitana de Santiago de Chile. Estudios Geográficos, LXX (266), 181-203.

IGAC. (2013). Descripción y corrección de productos Landsat 8 LCDM. Bogotá, Colombia. Version 1.0.

Jiménez, A. (2017). Planificación urbana en Costa Rica: Apuntes sobre nuestra forma de hacer ciudad en el último siglo. Recuperado de https://urbe21blog.wordpress.com/2017/01/08/planificacion-urbana-en-costa-rica/ Kruse, F.A. (2004). Comparison of ATREM, ACORN, and FLAASH atmospheric corrections using low-altitude AVIRIS data of Boulder, CO. Recuperado de http://ww.w.hgimaging.com/PDF/KruseJPL2004_ATM_Compare.pdf: junio 2015

Lahoz, E. (2010). Reflexiones medioambientales de la expansión urbana. Cuadernos Geográficos, 46 (1), 293-313.

Lungo, M. (1999). Gestión de la tierra y planificación urbana en San Salvador y Panamá. Lincoln Institute Research Report. San salvador, El Salvador. Lungo, M. (2000). Ciudad grande, país pequeño: Los desafíos de la gestión metropolitana en Centroamérica. Repensando la experiencia urbana de América Latina: questóes, conceitos e valroes, A.C. CLACSO, Buenos Aires.

Lungo, M. (2001). Centroamérica: La ciudad y sus vulnerabilidades. Quórum, 3 (17), 53-59.

Moura, R., \& de F. Firkowski, O. L. (2007). La Dimensión Regional de las Aglomeraciones Urbanas Brasileñas y los Retos de Gestión. PAMPA, 1(3), 121-144. https://doi.org/10.14409/pampa.v1i3.3144

Orozco, R., Vargas, C., Vargas, A. \& Aguilar, J. (2015). Crecimiento de las principales áreas metropolitanas de Centroamérica. Informe final de investigación para el Quinto Informe Estado de la Región. San José, Costa Rica: Programa Estado de la Nación.

Ospina, G. (2013). Migraciones campo-ciudad en el MAGREB. UNISCI Discussion Papers, (31), 69-90.

Pujol, R., \& Pérez, E. (2012). Crecimiento urbano en la región metropolitana de San José, Costa Rica: Una exploración espacial y temporal de los determinantes del cambio de uso del suelo, 1986-2010. Documento de Trabajo del Lincoln Institute of Land Policy. Lincoln Institute Product Code: WP13RP1SP. 
Christian Vargas-Bolaños - Ricardo Orozco-Montoya - Annie Vargas-Hernández - Jairo Aguilar-Arias

Methodology for determining the growth of urban sprawl in the capital

cities of the Central American region (1975-1995-2014)

Programa Estado de la Nación. (2013). XIX Estado de la Nación. San José, Programa Estado de la Nación.

Programa Estado de la Nación. (2014). XX Estado de la Nación. San José, Programa Estado de la Nación.

Programa Estado de la Nación. (2016). Quinto Informe Estado de la Región en Desarrollo Humano Sostenible. San José, Programa Estado de la Nación.

Programa GEOSUR (Red Geoespacial de América Latina y el Caribe). (2013). Base de datos espaciales. Recuperado de https://www. geosur.info/geosur/index.php/es/?Itemid=470\&option=com_service statuschecker\&view $=$ servicestatus\&servicetype $=$ wfs

Richards, J. (2013). Remote Sensing Digital Image Analysis. Australia: Editorial Springer. Quinta edición.

Rivadeneira, L. (2001). Guatemala: población y desarrollo, un diagnóstico demográfico. Secretaría de Planificación y programación (SEGEPLAN) y Centro Latinoamericano y Caribeño de Demografía (CE$L A D E)$. Santiago de Chile.

Serrano, J. (2007). Crecimiento y consolidación de las principales aglomeraciones urbanas españolas. Investigaciones Geográficas, 44, 33-54.

Smith, C. (1991). El patrón de urbanización de Centroamérica en el siglo XIX. Anuario de Estudios Centroamericanos, 17 (1), 21-46.

Torres, M. (2008). La construcción de la nueva capital de Belice, Belmopán. Jornadas Estudiantiles Latinoamericanas. México.

Uribe, A., Marín, M., Morales, N., Baires, S. \& Zeitún, E. (2010). Notas técnicas sobre tendencias del crecimiento urbano en Centroamérica. Informe final de investigación para el Cuarto Informe Estado de la Región. San José, Costa Rica: Programa Estado de la Nación.

Urzúa, M. (2015). Gestión de los servicios urbanos en Centroamérica. Informe final de investigación para el Quinto Informe Estado de la Región. San José, Costa Rica: Programa Estado de la Nación.

Williams, J. (2004). Sistemas urbanos en América Latina: Globalización y Urbanización. Cuadernos de Geografía, (13), 41-58.

Word Population. (2015). 2015 Word Population Data Sheet: whit a special focus on women's empowerment. Recuperado de http://www. prb.org/pdf15/2015-world-population-data-sheet_eng.pdf 
